\title{
Application of IR Thermography with Thermal Diffusivity Analysis for Detection of Plies Displacement in CFRP Composites
}

\author{
Sebastian Pawlak \\ (Submitted June 17, 2016; in revised form October 1, 2018; published online November 14, 2018)
}

\begin{abstract}
This paper presents an efficient nondestructive testing (NDT) method for detection of plies displacement in carbon fiber reinforced plastic (CFRP) composites using the active thermography technique. To assess the capability of the proposed technique for detection of plies displacement, the CFRP composite specimens with simulated fault were designed and manufactured. The IR thermography measurements were conducted using two-sided experimental arrangement. From recorded sequences of thermal images, the temperature variations versus time plots were extracted to obtain the maximum thermal contrasts. For quantitative interpretation of the results, the thermal diffusivity values for each composite material were determined and related to the fiber volume fraction. The experimental results showed that the thermal diffusivity increases with an increase of fiber volume fraction; further, the values of thermal diffusivity are specimen thickness dependent. The obtained values of thermal diffusivity varied from $1.5 \times 10^{-7} \mathrm{~m}^{2} / \mathrm{s}$ (for $3.2 \mathrm{~mm}$ composite with 8.5 vol.\% carbon fiber) to $2.6 \times 10^{-7} \mathrm{~m}^{2} / \mathrm{s}$ (for $7.7 \mathrm{~mm}$ composite with 34.1 vol.\% carbon fiber). On the basis of these results, it was concluded that the active thermography combined with thermal diffusivity analysis can be considered as a reliable NDT technique for detection of plies displacement in CFRP composites.
\end{abstract}

Keywords active thermography, CFRP composites, plies displacement, thermal contrast, thermal diffusivity

\section{Introduction}

The nondestructive testing (NDT) of polymer composite materials after manufacture is an important issue especially for the aircraft industry, since the production processes have the potential to introduce a variety of defects. For example, in Resin Transfer Molding (RTM) process, a typical problem is the displacement of plies, which may occur during resin flow in closed mold (Ref 1). When resin is injected into the closed mold, the reinforcement has a tendency to be displaced from an initial position due to injection pressure or resin viscosity (Ref $1,2)$. This undesirable phenomenon leads to a component with unacceptable physical and mechanical properties. It has been reported that the displacement of plies can be detected by using, for example, the ultrasonic testing (Ref 3 ). However, due to the time-consuming nature of scanning procedure using ultrasonic testing, especially in the case of large components, there is a need to develop a reliable and efficient NDT technique able to detect such faults in advanced polymer composite materials.

This work presents the application of active thermography technique, using both thermal contrast and thermal diffusivity analysis, for detection of plies displacement in carbon fiber

Sebastian Pawlak, Institute of Thermal Technology, Silesian University of Technology, Konarskiego 22, 44-100 Gliwice, Poland. Contact e-mail: sebastian.pawlak@polsl.pl.

reinforced plastic (CFRP) composites. Nowadays, the active thermography is commonly used for assessing the composite materials in, for example, the aircraft industry (Ref 4, 5). In the field of NDT of polymer composites, this technique has been successfully used in several applications, i.e., detection of defects (Ref 6), delaminations (Ref 4), inclusions and impact damage (including barely visible impact damage) (Ref 5), evaluation of fatigue degradation (Ref 7). It is also a reliable and effective technique for evaluation of thermo-physical properties (Ref 8, 9), defect characterization (Ref 10, 11), testing of permanent joints (Ref 12, 13).

\section{Theoretical Background of the Method}

In the active thermography technique, a specimen (or other tested object) is subjected to usually strong, short-duration heating in order to achieve the specific thermal contrast, which is the parameter used for the detection of defects and their characterization. The maximum thermal contrast and the time of its appearance are usually put into relation with the defect position, defect size (or other parameters) to enable its assessment (Ref 14). There are different thermal contrasts used to obtain the maximum thermal contrast appearing during the temperature variations in the active thermography experiment (Ref 14). For example, most often used in NDT practice is the absolute thermal contrast $\Delta T_{\mathrm{a}}(t)$, which, at location of measurement point $p(x, y)$ and for time $t$, is defined as:

$\Delta T_{\mathrm{a}}(t)=T(t)-T_{\mathrm{r}}(t)$,

where $T(t)$ is the temperature at time $t$ for measurement point $p(x, y)$, and $T_{\mathrm{r}}(t)$ is the temperature at time $t$ for the reference point (usually the area of the specimen without defect) (Ref 15). 
For more information about thermal contrast definitions, the reader is referred to (Ref $11,14,15)$.

It is also possible to obtain fully quantitative results from thermographic measurements, for example, by performing the experiment in conditions, which enables to extract the thermal diffusivity data from recorded sequences of thermal images. Such a data analysis arises from analogy between the principle of pulsed thermography technique and principle of standard heat pulse method or "flash method" (Ref 16) for thermal diffusivity measurements (in the case when the experiment is performed using double-sided experimental arrangement, Fig. 1).

This analysis can be simply performed by using convenient procedure based on thermal diffusivity computation, described in the literature (Ref 16, 17). Parker et al. (Ref 16) in 1961 proposed a transient technique based on the heat pulse method or "flash method" to measure the thermal diffusivity of homogeneous materials. In this method, a uniform heat pulse of relatively short duration (compared to the time of temperature propagation through a material) is applied to heat the front surface of specimen and resulting temperature rise on the rear surface is recorded (Ref 16, 17). If the heat losses are neglected, the normalized temperature of rear surface is given by (Ref 16):

$U(L, t)=1+2 \sum_{n=1}^{\infty}(-1)^{n} \exp \left(-n^{2} \omega\right)$

where:

$\omega=\pi^{2} \alpha t / L^{2}$

and $U(L, t)$ are dimensionless parameters, $n$ is an integer, $\alpha$ is thermal diffusivity, $L$ is specimen thickness and

$U(L, t)=\Delta T(L, t) / \Delta T_{\mathrm{m}}$

where $\Delta T(L, t)$ is the temperature above ambient temperature at the time $t$ and $\Delta T_{\mathrm{m}}$ is the maximum temperature rise.

Parker et al. (Ref 16) suggested to determine the thermal diffusivity from Eq. 2 and from dimensionless temperature history on the rear surface of the specimen (Fig. 2).

At a half the maximum temperature rise $(U=0.5), \omega_{0.5}$ is equal to 1.38 , and the thermal diffusivity can be calculated using equation (Ref 16):

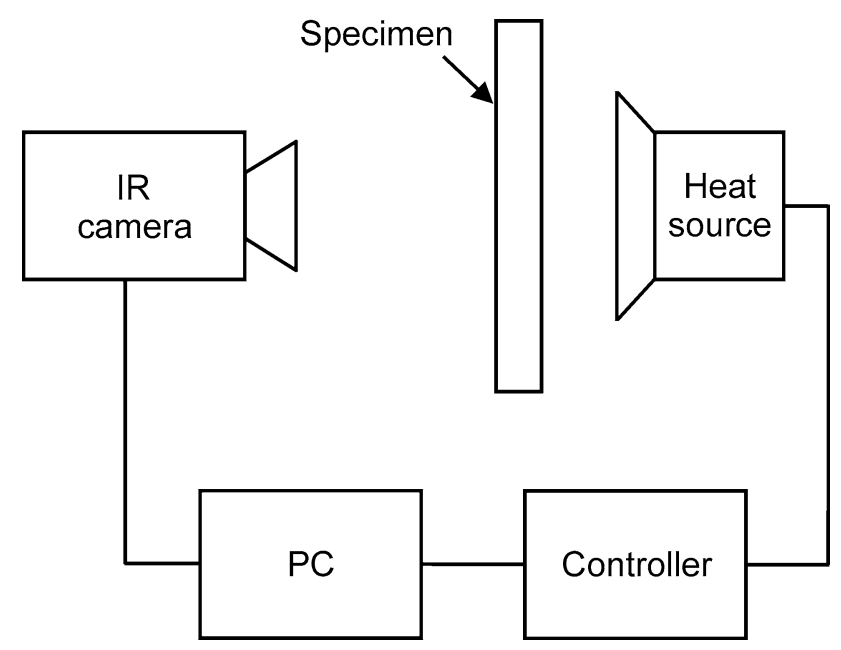

Fig. 1 Scheme for double-sided active thermography experimental arrangement $\alpha=1.38 L^{2} / \pi^{2} t_{0.5}$

where $t_{0.5}$ is the time to reach half maximum temperature rise.

The described methods of data analysis were used in the present study to analyze the obtained results from thermographic measurements.

\section{Material and Experimental Procedure}

In order to assess the suitability of the active thermography for detection of plies displacement, the CFRP composite specimens with artificially created fault were designed and manufactured. The displacement of plies was simulated by joining together (adhesive butt joint) two different composite plates $(100$ by $100 \mathrm{~mm}$ ) having both the different number of carbon fabric layers and the same total thickness, as shown in Fig. 3. Several specimens of different thicknesses from about 3.2 to $7.7 \mathrm{~mm}$ were prepared to assess the capability of considered technique and also to investigate the effect of specimen thickness on obtained experimental results. Such a range of thickness was selected taking into account typical thicknesses of CFRP products fabricated by RTM process, as well as data for CFRP specimens found in the literature (Ref 5).

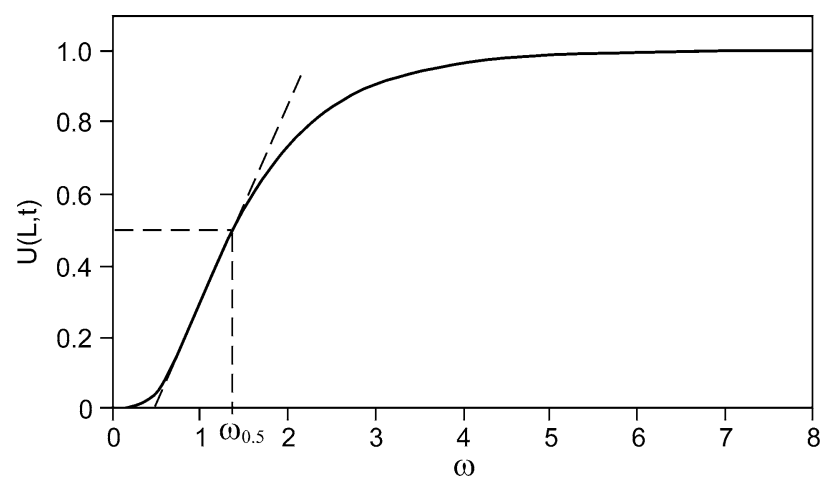

Fig. 2 Dimensionless temperature history on the rear surface of the specimen $(\operatorname{Ref} 16,17)$

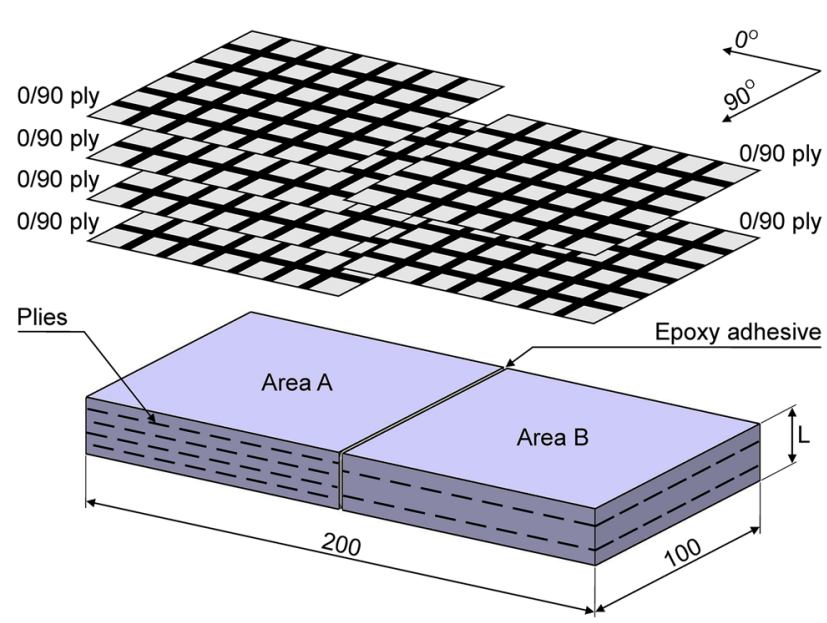

Fig. 3 Ply layout and model of example CFRP composite specimen 
The composite plates were manufactured by layup in a twopart flat mold, using the following constituent materials: plain woven carbon fabric Sigratex (SGL Carbon Group, Germany), epoxy resin Epidian ${ }^{\circledR} 53$ cured with hardener Z-1 (both from Z. Ch. "Organika-Sarzyna," Poland). Each composite material was produced with identical ply layout (i.e., bidirectional laminate), as shown in Fig. 3. As an adhesive for joining two composite plates, the same epoxy resin was applied as was used for composites manufacturing. The selected properties of constituent materials are shown in Table 1.

The details of prepared specimens, together with their symbols (related to the rounded thickness in millimeters and number of plies, respectively), are shown in Table 2. For the thermographic measurements, all specimens were painted with a thin matt-black coating with an emissivity value of about 0.92 in order to ensure homogeneity in the specimen surface emissivity.

The active thermography experiment was planned taking into consideration the thermal properties of materials tested and further possibility of extracting the thermal diffusivity data from sequences of thermal images. For those reasons, a twosided inspection (Fig. 1) using long-pulse approach was applied to obtain the temperature-time plots required to evaluate a maximum thermal contrast. The method consists of heating the front surface of the specimen using uniform heating and measuring the temperature evolution on the rear surface with infrared (IR) camera. To provide an accuracy and repeatability of the measurements, an automated test stand (Fig. 4) was used.

The apparatus was designed to provide a uniform heating of specimen surface without its edges by using a thermal shield (the heated area was smaller than the specimen surface). As a thermal wave source, a $1.2 \mathrm{~kW}$ IR radiator with surface dimensions of $250 \times 62 \mathrm{~mm}$ and wavelength range of 2 $10 \mu \mathrm{m}$ was used. Since the IR radiator is unable to turn on/off instantaneously, it was mounted on moveable platform, which enabled it to move back the radiator after heating. To provide a

Table 1 Properties of constituent materials

\begin{tabular}{lll}
\hline Parameter & Carbon fiber & Epoxy resin \\
\hline Density & $1650\left(\mathrm{~kg} / \mathrm{m}^{3}\right)$ & $1130\left(\mathrm{~kg} / \mathrm{m}^{3}\right)$ \\
Fabric areal weight & $0.24\left(\mathrm{~kg} / \mathrm{m}^{2}\right)$ & $\ldots$ \\
Thermal conductivity & $\sim 15.0(\mathrm{~W} / \mathrm{mK})$ & $0.2(\mathrm{~W} / \mathrm{mK})$ \\
\hline
\end{tabular}

square-shaped heating pulse, a shutter was placed between front surface of the specimen and the IR radiator. The duration of the heating was controlled with PLC controller, which allowed to setting up the exact heating time. The thermal images were recorded at a rate of 7.5 measurements per second using IR camera ThermaCAM ${ }^{\mathrm{TM}}$ SC640 (Flir Systems) with focal plane array (FPA) detector. Data acquisition and analysis were performed using Researcher Professional 2.9 software. The heating time (varied depending on specimen thickness) and the distance between IR radiator and surface of the specimen $(30 \mathrm{~mm})$ were determined experimentally when the temperature rise on the rear surface for each specimen was satisfactory for the measurements (taking into consideration achieved values of maximum thermal contrast and subsequent feasibility of extracting the thermal diffusivity data). The distance from the specimen to the IR camera was approximately $0.5 \mathrm{~m}$.

\section{Results and Discussion}

The results from thermographic measurements are presented in the form of temperature variations versus time plots $T(t)$ with resulting absolute thermal contrasts. Two areas of the specimen, shown in Fig. 5, were taken into consideration during the

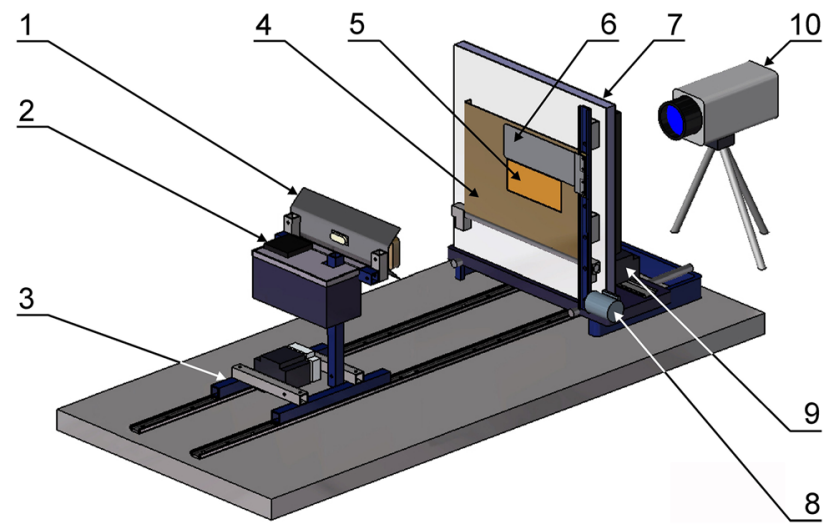

Fig. 4 Apparatus for active thermography measurements; 1-IR radiator, 2-temperature control unit, 3-moveable platform, 4-specimen holder with thermal shield, 5-specimen, 6-shutter, 7-temperature barrier (background), 8-drive of shutter, 9-PLC controller, 10-IR camera

Table 2 General properties of the specimens

\begin{tabular}{lcccr}
\hline Specimen no. & Specimen area & Thickness, mm & Number of plies & Fiber volume fraction, vol.\% \\
\hline 1 & A (CFRP304) & 3.23 & 4 & 16.9 \\
& B (CFRP302) & & 2 & 8.5 \\
2 & A (CFRP408) & 4.19 & 8 & 26.1 \\
3 & B (CFRP404) & & 4 & 13.0 \\
& A (CFRP510) & 4.85 & 10 & 28.4 \\
4 & B (CFRP507) & & 7 & 22.0 \\
5 & A (CFRP610) & 6.20 & 10 & 13.5 \\
& B (CFRP606) & & 6 & 34.1 \\
& A (CFRP819) & 7.70 & 19 & 21.2 \\
\hline
\end{tabular}




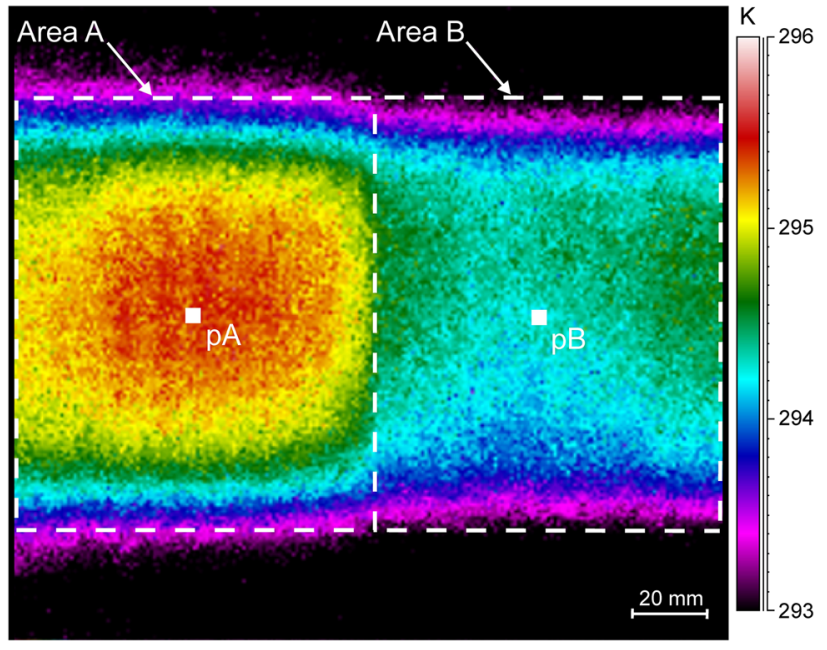

Fig. 5 Example thermal image of the rear surface of specimen with analyzed areas

thermographic experiment and subsequent data analysis. Area A (left) corresponded to the composite with higher number of plies, while area B (right) corresponded to the composite with lower number of plies (Fig. 5). Figure 5 represents, as an example, a thermal image of the 6.2-mm-thick specimen, captured near the maximum thermal contrast between the two analyzed areas (A and B), after approximately $33 \mathrm{~s}$ counting from the beginning of heating process. The boundary between these areas is clearly recognizable in the presented thermal image, demonstrating the capability of the proposed technique for detection of plies displacement. The cross-sectional view of all specimens tested is illustrated in Fig. 6, showing the adhesive butt joints and actual ply layout for different composite plates.

To obtain the maximum thermal contrast values, further analysis has been performed on the basis of recorded sequences of thermal images. Two measurement points, $\mathrm{pA}$ and $\mathrm{pB}$, located in the center of area A and area B, respectively (Fig. 5), were selected to extract the temperature-time plots required for absolute thermal contrast evaluation. The obtained temperature-time plots with resulting thermal contrast $\Delta T_{\mathrm{a}}(t)$ for each specimen are depicted in Fig. 7, 8, 9, 10 and 11.

It can be seen in Fig. 7, 8, 9, 10 and 11 that for all specimens tested the measurements gave, in general, the comparable results taking into account the characteristic peak-shaped plot of the thermal contrast, as a result of different temperature rise rate between both analyzed areas (A and B). All temperaturetime plots show that the higher the carbon fiber volume fraction $\left(V_{\mathrm{f}}\right)$, the higher is the temperature rise rate (Fig. 7, 8, 9, 10 and 11). It can be attributed to a higher thermal conductivity/ diffusivity for the composites with higher carbon volume fraction. The obtained maximum thermal contrast values, greater than $0.5 \mathrm{~K}$ (Table 3 ) in all considered cases, show the existence of significant variations in thermal properties between two analyzed areas. The obtained maximum thermal contrast values together with the time of its appearance are shown in Table 3.

To explain the differences in obtained temperature-time plots (different temperature rise rates) between both areas of the specimen, the thermal diffusivity values were determined using Parker's method (Ref 16). From all presented plots of

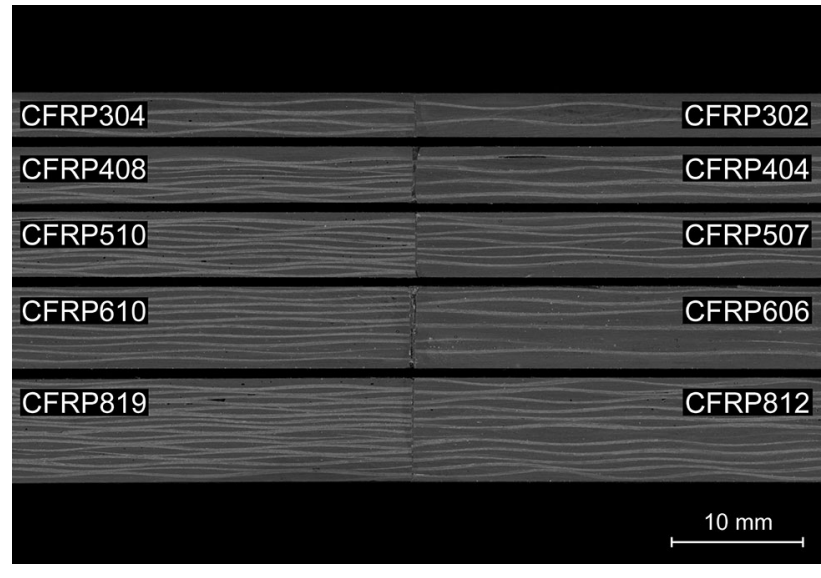

Fig. 6 Cross-sectional view of the investigated specimens

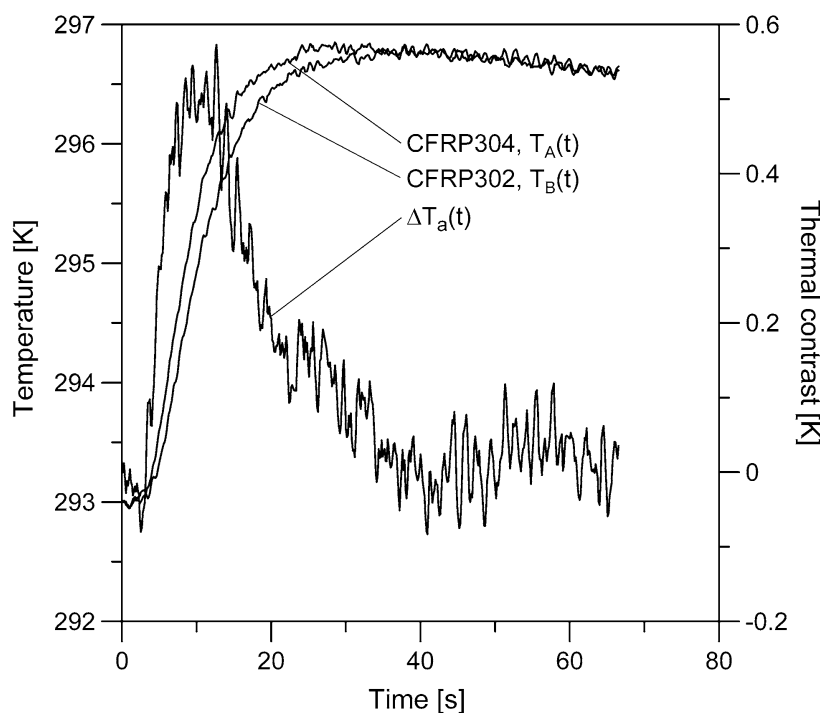

Fig. 7 Temperature variations vs time for specimen 1 with resulting thermal contrast between area A (CFRP304) and area B (CFRP302); heating time of $1.0 \mathrm{~s}$

temperature variations versus time, the dimensionless temperature history plots were created to obtain the $t_{0.5}$ values required for the thermal diffusivity calculations, according to the procedure described earlier. The $t_{0.5}$ values taken from normalized temperature increase plots together with specimen thickness $(L)$ were used to calculate the thermal diffusivity values according to Eq. 5. The determined values of the thermal diffusivity are shown in Table 3.

It can be seen from Table 3 that for all considered specimens, the maximum thermal contrast values are satisfactory for the investigations, leading to proper interpretation. The differences between values of time to appearance of maximum thermal contrast can be attributed to the thickness of the specimens. Presented values of thermal diffusivity for both areas (A and B) clarify the obtained thermal contrasts as a result of unsteady-state heat transfer in a material with locally different thermal properties. A comparison of obtained thermal diffusivity values related to carbon fiber volume fraction in given area of the specimens is depicted in Fig. 12. This figure shows that there is a common trend concerning the 


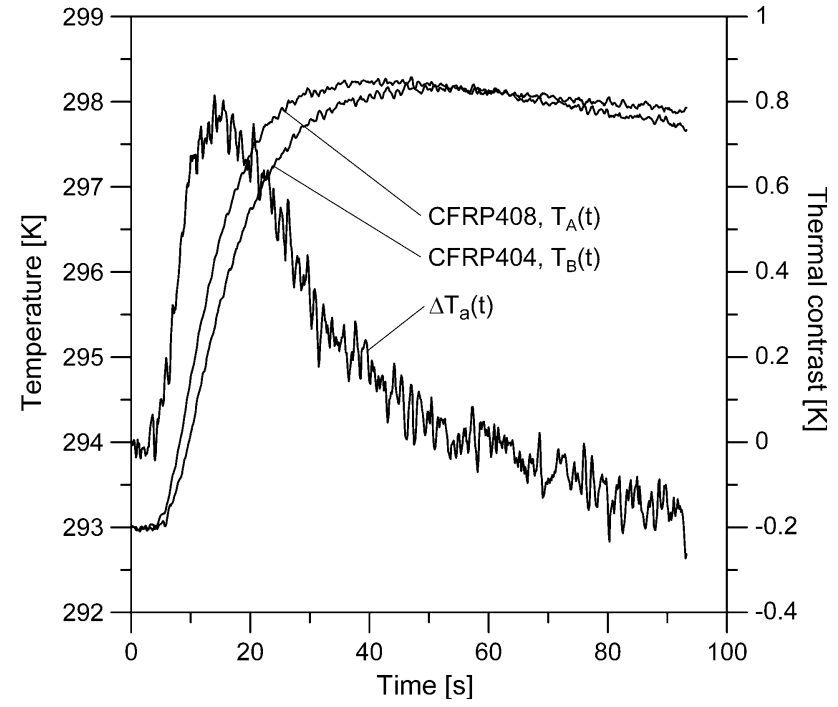

Fig. 8 Temperature variations vs time for specimen 2 with resulting thermal contrast between area A (CFRP408) and area B (CFRP404); heating time of $2.0 \mathrm{~s}$

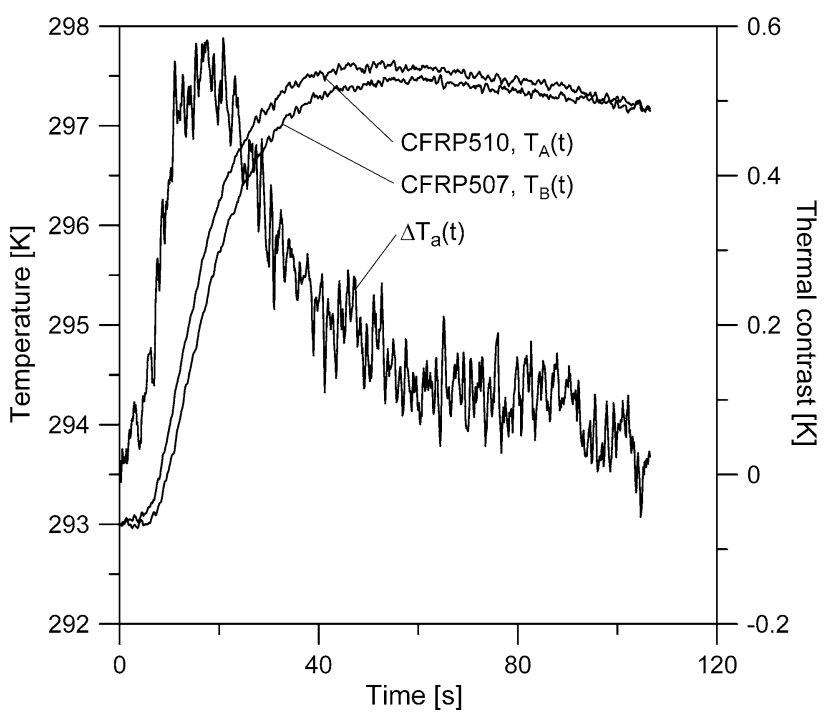

Fig. 9 Temperature variations vs time for specimen 3 with resulting thermal contrast between area A (CFRP510) and area B (CFRP507); heating time of $2.0 \mathrm{~s}$

thermal diffusivity dependence with fiber volume fraction for all specimens tested. As expected, these results show that the thermal diffusivity increases with an increase of fiber volume fraction. This is due to a higher (about two orders of magnitude) thermal conductivity of carbon fiber in comparison with thermal conductivity of epoxy matrix (see Table 1).

Due to the relatively low fiber volume fraction of specimens tested, it is difficult to compare the obtained values of thermal diffusivity with those presented in the literature; for example, Navarrete et al. (Ref 18) reported the value of $3.31 \times 10^{-7} \mathrm{~m}^{2} /$ $\mathrm{s}$ for CFRP composite with 50 vol.\% carbon fiber, obtained by using "flash method." On the other hand, because of the fact that measured values of the thermal diffusivity are specimen thickness dependent, as stated by Hasselman and Donaldson (Ref 19), the values achieved during the present measurements are expected to deviate from the true values. This phenomenon

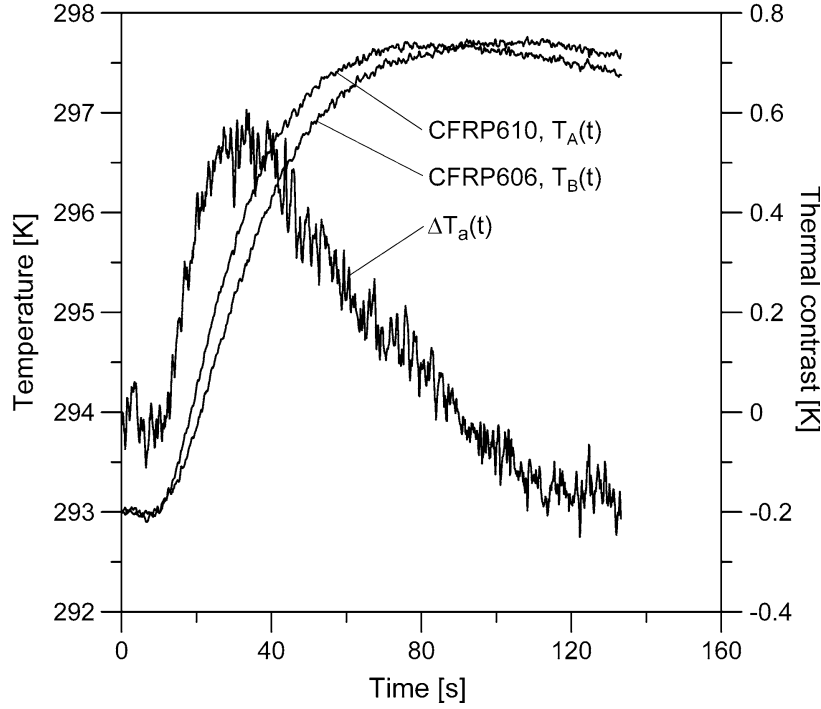

Fig. 10 Temperature variations vs time for specimen 4 with resulting thermal contrast between area A (CFRP610) and area B (CFRP606); heating time of $3.0 \mathrm{~s}$

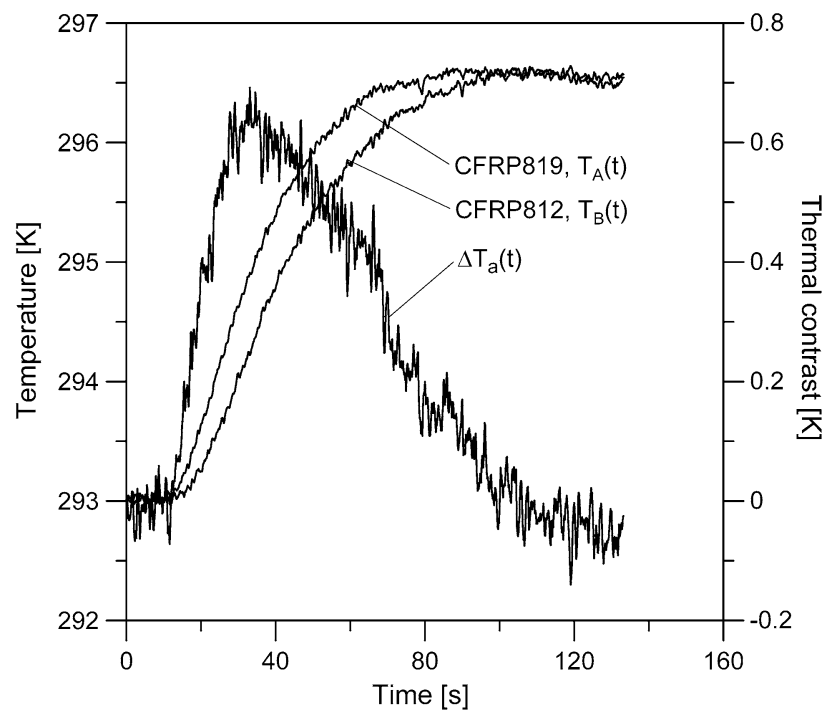

Fig. 11 Temperature variations vs time for specimen 5 with resulting thermal contrast between area A (CFRP819) and area B (CFRP812); heating time of $3.0 \mathrm{~s}$

can be clearly observed in Fig. 12, when comparing the results for specimen 5 (possessing the greatest thickness) with results obtained for thinner specimens. It can be attributed to increasing heat losses (during the measurement) with increasing thickness (size) of the specimen (Ref 19). The above observation shows that a real parameter determined in the present experiment was the apparent thermal diffusivity, which is of little importance taking into account the purpose of the present study.

The presented results demonstrate the potential of the proposed technique (on the basis of thermal contrast and thermal diffusivity analysis) for detection of plies displacement in flat CFRP composites. In practice, due to usually complex shape and size of the real composite components, it is difficult to provide such uniform heating of the surface as was done in 
Table 3 Investigation results

\begin{tabular}{|c|c|c|c|c|}
\hline Specimen no. & Specimen area & Maximum thermal contrast, $K$ & Time to appearance, $\mathbf{s}^{*}$ & Thermal diffusivity $\times 10^{-7}, \mathrm{~m}^{2} / \mathrm{s}$ \\
\hline \multirow[t]{2}{*}{1} & A (CFRP304) & 0.56 & 12.4 & 1.69 \\
\hline & B (CFRP302) & & & 1.50 \\
\hline \multirow[t]{2}{*}{2} & A (CFRP408) & 0.79 & 15.2 & 1.99 \\
\hline & B (CFRP404) & & & 1.63 \\
\hline \multirow[t]{2}{*}{3} & A (CFRP510) & 0.58 & 15.3 & 2.15 \\
\hline & B (CFRP507) & & & 1.88 \\
\hline \multirow[t]{2}{*}{4} & A (CFRP610) & 0.61 & 33.1 & 1.98 \\
\hline & B (CFRP606) & & & 1.72 \\
\hline \multirow[t]{2}{*}{5} & A (CFRP819) & 0.69 & 33.2 & 2.60 \\
\hline & B (CFRP812) & & & 2.11 \\
\hline
\end{tabular}

*Time to reach the maximum thermal contrast

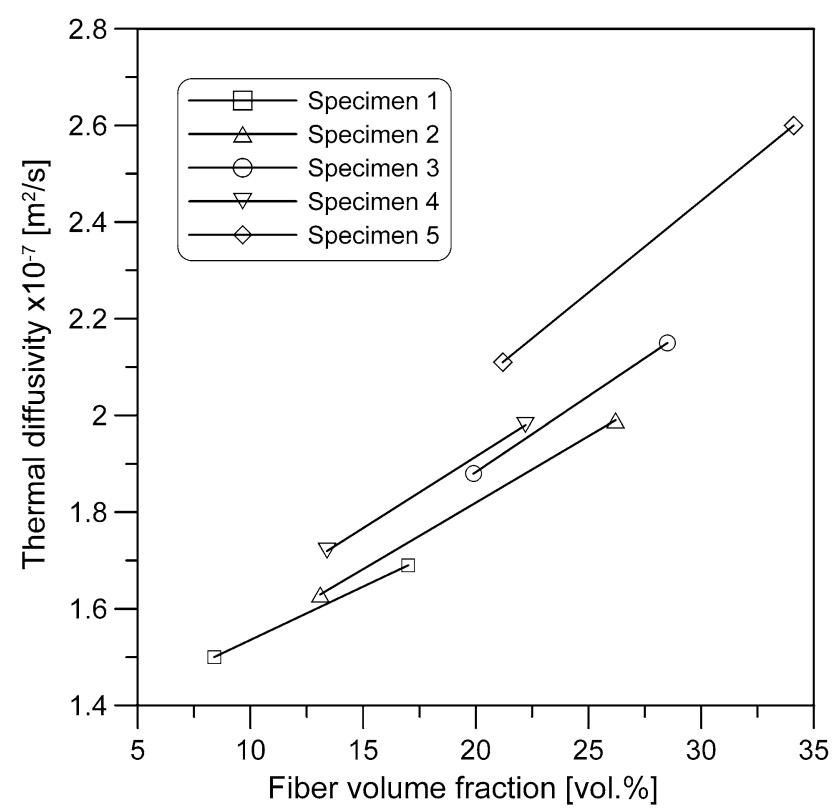

Fig. 12 Comparison of thermal diffusivity values related to carbon fiber volume fraction

the present experiment; therefore, it is recommended to perform the thermographic experiment in conditions, which enables to obtain the thermal diffusivity data for reliable characterization of the material.

\section{Conclusions}

In the present study, the methodology based on active thermography technique combined with thermal diffusivity analysis was applied for detection of plies displacement in CFRP composites. The main conclusions are summarized as follows:

1. The simulated fault in each composite specimen was detected directly by observing the sequences of thermal images captured after about 10 to $30 \mathrm{~s}$ (depending on specimen thickness), counting from the beginning of the heating phase.

2. The analysis of obtained temperature-time plots showed that the variation of number of plies between two areas of the specimen caused the different temperature rise rates (due to locally different thermal properties), resulting with appearance of characteristic peak-shaped plot of the thermal contrast. Further analysis showed that the obtained maximum thermal contrast values for all specimens tested were higher than $0.5 \mathrm{~K}$, which is satisfactory for nondestructive testing using active thermography.

3. Subsequent quantitative analysis of the results, based on standard procedure for thermal diffusivity determination, showed that the thermal diffusivity increases with an increase of fiber volume fraction, and further, the values of thermal diffusivity are specimen thickness dependent. For two selected specimens with different thickness and similar fiber volume fraction (i.e., $4.2 \mathrm{~mm}$ composite with 13.0 vol.\% carbon fiber and $6.2 \mathrm{~mm}$ composite with 13.5 vol. $\%$ carbon fiber), higher value (about 5\% difference) of thermal diffusivity was obtained for composite with higher thickness. The experimental values of thermal diffusivity varied from $1.5 \times 10^{-7} \mathrm{~m}^{2} / \mathrm{s}$ (for $3.2 \mathrm{~mm}$ composite with $8.5 \mathrm{vol} \%$ carbon fiber) to $2.6 \times 10^{-7} \mathrm{~m}^{2} / \mathrm{s}$ (for $7.7 \mathrm{~mm}$ composite with 34.1 vol. $\%$ carbon fiber).

4. On the basis of obtained results, it was concluded that active IR thermography can be considered as a suitable nondestructive testing technique for detection of plies displacement in CFRP composite materials giving quantitative results.

\section{Open Access}

This article is distributed under the terms of the Creative Commons Attribution 4.0 International License (http://creativeco mmons.org/licenses/by/4.0/), which permits unrestricted use, distribution, and reproduction in any medium, provided you give appropriate credit to the original author(s) and the source, provide a link to the Creative Commons license, and indicate if changes were made. 


\section{References}

1. M.O.W. Richardson and Z.Y. Zhang, Experimental Investigation and Flow Visualisation of the Resin Transfer Mould Filling Process for Non-woven Hemp Reinforced Phenolic Composites, Compos. Part A Appl. Sci. Manuf., 2000, 31(12), p 1303-1310

2. S. Laurenzi, M. Marchetti, Advanced composite materials by resin transfer molding for aerospace applications, Composites and Their Properties, Chapter 10, p 197-226. http://dx.doi.org/10.5772/48172, 2012. Accessed 3 June 2016

3. Raport: Best Manufacturing Practices, McDonnell Douglas Aerospace St. Louis, MO, College Park, Maryland, May 1995, http://www.bmpc oe.org/bestpractices/pdf/mdasl.pdf, 1995. Accessed 10 June 2016

4. N.P. Avdelidis, D.P. Almond, A. Dobbinson, B.C. Hawtin, C. IbarraCastanedo, and X. Maldague, Aircraft Composite Assessment by Means of Transient Thermal NDT, Prog. Aerosp. Sci., 2004, 40(3), p 143-162

5. D. Bates, G. Smith, D. Lu, and J. Hewitt, Rapid Thermal Nondestructive Testing of Aircraft Components, Compos. Part B Eng., 2000, 31(3), p 175-185

6. S.A. Keo, F. Brachelet, F. Breaban, and D. Defer, Defect Detection in CFRP by Infrared Thermography with $\mathrm{CO}_{2}$ Laser Excitation Compared to Conventional Lock-In Infrared Thermography, Compos. Part B Eng., 2015, 2015(69), p 1-5

7. G. Muzia, Z. Rdzawski, M. Rojek, J. Stabik, and G. Wróbel, Thermographic Diagnosis of Fatigue Degradation of Epoxy-Glass Composites, J. Achiev. Mater. Manuf. Eng., 2007, 24(2), p 123-126

8. K. Kochanowski, W. Oliferuk, Z. Płochocki, and A. Adamowicz, Determination of Thermal Diffusivity of Austenitic Steel Using Pulsed Infrared Thermography, Arch. Metall. Mater., 2014, 59(3), p 893-897

9. W.P. Adamczyk, R.A. Białecki, and T. Kruczek, Retrieving Thermal Conductivities of Isotropic and Orthotropic Materials, Appl. Math. Model., 2016, 40(4), p 3410-3421
10. O. Wysocka-Fotek, M. Maj, and W. Oliferuk, Use of Pulsed IR Thermography for Determination of Size and Depth of Subsurface Defect Taking Into Account the Shape of Its Cross-Section Area, Arch. Metall. Mater., 2015, 60(2), p 615-620

11. S. Grys, New Thermal Contrast Definition for Defect Characterization by Active Thermography, Measurement, 2012, 45(7), p 1885-1892

12. C. Meola, G.M. Carlomagno, A. Squillace, and G. Giorleo, The Use of Infrared Thermography for Nondestructive Evaluation of Joints, Infrared Phys. Technol., 2004, 46(1-2), p 93-99

13. C. Maierhofer, M. Rollig, H. Steinfurth, M. Ziegler, M. Kreutzbruck, C. Scheuerlein, and S. Heck, Non-destructive Testing of $\mathrm{Cu}$ Solder Connections Using Active Thermography, NDT\&E Int., 2012, 52, p 103-111

14. M. Susa, X. Maldague, and I. Boras, Improved Method for Absolute Thermal Contrast Evaluation Using Source Distribution Image (SDI), Infrared Phys. Technol., 2010, 53(3), p 197-203

15. C. Ibarra-Castanedo, D. Gonzalez, M. Klein, M. Pilla, S. Vallerand, and $\mathrm{X}$. Maldague, Infrared Image Processing and Data Analysis, Infrared Phys. Technol., 2004, 46(1-2), p 75-83

16. W.J. Parker, R.J. Jenkins, C.P. Butter, and G.L. Abbot, Flash Method of Determining Thermal Diffusivity, Heat Capacity and Thermal Conductivity, J. Appl. Phys., 1961, 32(9), p 1679-1684

17. W.N. dos Santos, P. Mummery, and A. Wallwork, Thermal Diffusivity of Polymers by the Laser Flash Technique, Polym. Test., 2005, 24(5), p 628-634

18. M. Navarrete, F. Serranıa, and M. Villagran, Application of the Flash Method for the Thermal Characterisation of Woven Carbon Fibre Laminates, Mater. Des., 2001, 22(2), p 93-97

19. D.P.H. Hasselman and K.Y. Donaldson, Effects of Detector Nonlinearity and Specimen Size on the Apparent Thermal Diffusivity of NIST 8425 Graphite, Int. J. Thermophys., 1990, 11(3), p 573-585 